\title{
Managing Organizational Conflicts: A Phenomenological Study of Nurse/ Physician Conflicts in Nigerian Hospitals and their Impact on Managed Care Delivery
}

\section{Okhakhu EE*1, Okhakhu $\mathrm{AL}^{2}$ and Okhakhu $\mathrm{JOO}^{3}$}

${ }^{1}$ Business Administration Department, Ambrose Alli University, Ekpoma, EdoState, Nigeria

${ }^{2}$ ENT Department, University of Benin Teaching Hospital, Benin City, EdoState, Nigeria

${ }^{3}$ Public Health Department, University of Northern British Columbia, Canada

\begin{abstract}
This study builds on and analyzes the conclusions examined the relationships in how nurses resolve their conflicts with doctors. They conclude that "dominance approaches to conflict resolution are associated with low occupational stress levels, whereas the obliging and avoidance approaches are linked to higher stress" and that "seniority and status of nurses affect both their choice of conflict-resolution tactics and the associated stress and job satisfaction levels". This research furthers the investigation by sieving through the lived experiences of nurses and physicians in Nigeria to ascertain if cultural socializations complicate conflict resolution between nurses and physicians, and if it further adversely affects patient care delivery. This phenomenological study used five thematic questions to interview 100 nurses from five major healthcare facilities across the country, seeking their experience of inter-professional, personal, and ethical conflict in-care of patients. The findings suggest that in Nigeria, cultural socialization weigh heavily on how conflicts are handed, and have a negative impact on healthcare management/delivery. The perceived dominance or professional superiority of physicians over nurses has adverse effect on nursing. The research shows value for collegiality in patient care, and points to new direction in the understanding collaboration.
\end{abstract}

Keywords: Organizational conflicts; Physicians; Phenomenological study; Healthcare management; Ethical conflict

\section{Introduction}

Tabak et al. [1] study outlined the following as sources of conflicts between nurses and physicians: "gender differences; gaps in education and socio-economic status; lack of understanding and sympathy; and, of late, the clash when nurses try to take on more professional responsibility". These factors are relevant to the discourse and other prior research support Tabak and Koprak's last point since there is clear evidence that in the past, nurses' subordination to the doctors has gone unquestioned $[2,3]$

Another conflict factor is the truth that nursing is still largely a female profession while doctoring is still largely male, and physicians enjoy higher prestige. According to Corley [4], even if the perceived apprenticeship of nurses to physicians is gradually disappearing, its influence is still felt. Physicians appear authoritarian by not taking nurses' opinion and clinical experience into consideration; making nurses more apprehensive about challenging physician greater power and authority. This can make them hesitant to report changes in the patients' condition. If the patient's condition then deteriorates the nurse feels frustrated and regrets not having been more assertive or confident. Nurses desire a rich and mutually beneficial inter-professional communication with physicians [5] rather than the current dominoservo relationship. This not only illustrates a difference between doctor and nurse, says Corley [4], it also becomes an element in the conflict between them.

This is regrettable in so far as it diminishes the quality of patient care. From one perspective, nurses by virtue of their bedside care for the patient grow personal relationships; hear the unspoken and undiagnosed psychosocial problems that are not unrelated to the official diagnosis. This knowledge should enrich their nursing and compliment physician practice, whose roles can remain simply technical and emotionally neutral, without nursing inputs in the continuum of care. This is the long shot burning interest in this study.

\section{Problem statement}

How and to what extent does cultural socialization impinge on healthcare conflict management?

To what extent do these conflicts further emasculate the exceptional patient care experience?

\section{Research method}

This qualitative research instrument supports the purposive sampling objective, and is refined from a previous survey, the Health Professions Stress Inventory (HPSI), which has been used to measure job stress in Pharmacists and Registered Nurses (RN). The HPSI consists of 30 five-point Likert-style questions pertaining to stressful job situations, among which conflict is primary. Each of the 30 fivepoint Likert-scale items is scored from 0 to 4 . Studies utilizing the HPSI to measure job stress in RNs have reported Cronbach's alpha coefficients of 0.85 and 0.90 [6].

However, the exact HPSI survey was not used by the researchers. Only its dimensions, question types and intent to measure have guided this modified questionnaire to ensure that the research stays close to the knowledge base that has direct relevance to this current study, asking only the questions that help to unfold the phenomenon being studied

*Corresponding author: Emmarex Elemeiye Okhakhu, Business Administration Department, Ambrose Alli University, Ekpoma, EdoState, Nigeria, Tel: +2347089738575; E-mail: Emmarex@gmail.com

Receved February 05, 2014; Accepted July 24, 2014; Published July 31, 2014

Citation: Okhakhu EE, Okhakhu AL, Okhakhu JOO (2014) Managing Organizational Conflicts: A Phenomenological Study of Nurse/Physician Conflicts in Nigerian Hospitals and their Impact on Managed Care Delivery. J Entrepren Organiz Manag 3: 115. doi: 10.4172/2169-026X.1000115

Copyright: @ 2014 Okhakhu EE, et al. This is an open-access article distributed under the terms of the Creative Commons Attribution License, which permits unrestricted use, distribution, and reproduction in any medium, provided the original author and source are credited. 
[7], and by introducing elements of cultural socialization. The original HPSI survey is a public domain document on the National Library of Medicine, not needing protection. In this modified questionnaire, individual characteristics sought included age, sex, marital status, and the total number of years worked as RN. Workplace characteristics included employment status at the hospital (full time or part time), facility, type of unit (by medical specialty), average number of hours worked, average number of patients cared for, perceived quality of care provided, and inability to meet patient care needs resulting nursephysician conflicts.

This purposive research selected nurses, aged 23-53 years, who are information-rich key informants, knowledgeable in the issues explored in order to enter the world of their experience [8]. Therefore data were collected only from nurses "who have experienced the phenomenon, and can articulate their conscious experiences" [9]. A sample size, $\mathrm{n}=100$ nurse participants from five major hospitals were used. A factor that was weighed in considering the number of participants was the trade-off between breadth and depth. For example, a questionnaire taking 15 minutes to fill out might require many more participants than an in depth interview in phenomenology [10].

\section{Core questions}

1) Relate a particular inter-professional conflict you have had with a physician, and how it affected your patient-care job? 2). How does conflict affect you? What are your ways of coping? Give a practical example. 3). Growing up, what ways were you taught to handle conflicts with a) peers at school, b) siblings, c) with bullies? 4). How do you react to people who deliberately refuse to recognize, respect, or acknowledge your cognitive and professional opinion? 5). What does collaboration mean to you? Please suggest models for effective collaboration that you would welcome on the job

\section{Literature review}

Folger et al. [11] defined conflict as the "interaction of interdependent people who perceive incompatibility and the possibility of interference from others as a result of this incompatibility". Within healthcare, the presence of conflict and efforts to manage it effectively has been recognized as an important skill [12]. Almost [13] acknowledged persistent conflict among nursing co-workers as a serious issue in the profession, and one that is on the rise around the world [14,15]. While nurse-physician conflict may have many direct and indirect causes, Espeland [16] posits that persistent conflict is particularly linked to key challenges facing the field. These include increased burnout, decreased work satisfaction and team performance [17], increased medical errors and increased likelihood of turnover [18].

Brinkert [19] citing Wilmot and Hocker [20], indissolubly ties conflict to communication. Communication is central to conflict in that communication often creates conflict, reflects conflict and is the way in which it is productively or destructively managed. While conflict is often viewed as negative, it does have its positive functions, including clarifying important problems and relationships, altruisms shared tasks, and helping to overcome resentments while fostering mutual understanding. Conflict communication can be a major issue for physicians and nurses in end-of-life decision-making [21] and lifesustaining dialysis treatment [22]. Conflict patterns have also been documented among these professionals in intensive care units [23]. Ethical uncertainty has been linked to professional status ambiguity [24] and different basic approaches were noted for nurses and physicians [25]. With the introduction of new nursing positions: Clinical Nurse
Specialist (CNS) and Nurse Practitioners (NP), and Nurse Managers to facilitate nurse practice and to reclaim some roles that were previously medical, has been linked to conflict among these professionals [26].

Common in these conflict encounters is verbal abuse: a harsh language perceived to be derogatory or even condemnatory, meant to slight a person or a group is described by Buback [27] as horizontal violence. There is a high incidence of horizontal violence or bullying in nursing [28]. Although it is not uncommon for nurses to get attacked by patients, nurses are most concerned about aggression from nursing colleagues and physicians [28]. A common trigger for these conflicts is in the challenges of perspective-taking and the integration points of view. Nurse-physician conflicts may also result from different professional judgments [29], different goals or lack of goal clarity [30], different experience levels [31] and tensions around status relations [32].

Vertical violence and tensions relating to administration, finances and patient care are also notable. Aggressive tactics directed from an actual or perceived superior towards someone of lower rank, is known as vertical violence [24]. Vertical violence often occurs in front of others; it has been documented as occurring in the operating room by surgeons towards nurses [24] and has been labelled surgical personality [33]. Vertical violence can be a source of tension and conflict [34].

The review of the literature shows that unmanaged conflict is costly not only in a monetary sense and not only for nurses. Arford [35] summarized the steep costs of nurse-physician conflict by pointing out the links to medication errors [36], patient injuries [37] and patient deaths [38]. Earlier, Gerardi provided extensive listings of direct and indirect costs of conflict. Direct costs of conflict includes litigation costs, lost management productivity, employee turnover costs, disability and worker compensation claims, regulatory fines or loss of contracts or provider status, increased care expenditures to handle adverse patient outcomes and intentional damage to property. Indirect costs of conflict included damaged team morale, lost opportunities to manage futureoriented projects, costs to patients, cost to reputation loss of market position, increased incidence of disruptive behaviour by organizational insiders and emotional costs.

The adverse effects of continual conflict are a major concern [13]. For example, workplace conflict has been linked to decreased work satisfaction and team performance in nursing [17]. It damages the work climate as well as the individual, both physically and psychologically [39]. Persistent conflict results in higher turn-over and absenteeism, lower coordination and collaboration and lower efficiency [40]. Specifically, verbal abuse has been shown to negatively impact patient care, work satisfaction and turnover rates [41] as well as morale, productivity and error rates [42]. It seems that directly addressing these important issues may be beneficial to nursing and physician practice, besides finding out how cultural socializations complicate the resolution of these conflicts.

\section{Analysis and Thematic Narratives}

Nine categories of possible conflict areas were created based on the interviews:

- sharing of information concerning the patient's condition,

- mutual understanding of the patient's feelings,

- joint participation in planning,

- common objectives,

- joint resolution of problems, 
- trust and respect,

- awareness of role and responsibility,

- mutual support and

- open communication.

After a fourth review of the raw data, the categories 'sharing of information concerning the patient's condition' and 'mutual understanding of patient's feelings' were combined into the category

a. 'sharing of patient information'; 'joint participation in planning,' 'common objective,' and 'joint resolution of problems' were combined into the category

b. 'joint participation in the cure/care decision-making process;' and 'trust and respect,' 'awareness of role and responsibility', 'mutual support', and 'open communication' were combined into the category

c. 'cooperativeness'. These three new categories aptly describe the thorny areas in nurse-physician conflicts and collaboration.

From these new categories we further distilled nurses' conflict behaviours/reaction patterns into some of Rahim and Bonoma's models [43]:

\section{Obliging}

This approach accentuates the other party's concern, and lowers the 'obligers' concerns by setting aside the urge to confront, thus demonstrating a degree of self-sacrifice and compliance with the wishes/needs of the other party. This approach is appropriate when one side believes they may be in error or that the issue is more important to the other side. It is also useful if one party is ready to give way on a certain point, in the belief that the other side will return the favour later. With this tactic the nurse tries (not always successfully) to meet the doctor's wishes by setting aside her own opinion. 'I try to fulfil the doctor's wishes'.

The raw data show clearly that when the interviewed nurses oblige, they do it with resentment knowing the favour will never be returned. The resentment is processed and leads to interpersonal and professional conflicts-in-care. A nurse narrated her experience: a doctor gave a wrong prescription so I called his attention to rewrite it, hoping it was an oversight. The physician became furious and verbally abusive but at the end of the day, it was actually a wrong prescription. The problem was later resolved by a consultant.

In another instance, a nurse shared her experience concerning an orthopaedic patient who had a bilateral hip replacement. The physician orders instructed that patient be not moved for any reason. Yet this nurse was conflicted by the order since the patient began to develop skin breakdown and bedsores, which prolonged the patients' hospitalization. A worrisome $30 \%$ of nurses shared similar experiences about physicians' orders. Beneath these rough professional dynamics are the potential dangers of medical errors that may be fatal, or lead to protracted hospitalizations.

\section{Dominance}

This is the opposite of Obliging, where any party in the conflict exhibits high self-interest and lowers or undermine the other-party's concern, using coercion to ensure that their viewpoint supersedes. Oftentimes, the dominance approach uses the argumentum ad expertite, couching the viewpoint with irrelevant academics/experience to silence the other partner, which is in fact a mockery.
Nurses accused physicians of this domineering approach in their practice of medicine and patient care. Nurses narrated instances when they were excused from patient's bedside because they suggested a different clinical idea. The doctor bellowed at the nurse 'I have done this for 15 years', asking the nurse to leave, in the presence of the listening patient. In this particular case, the nurse was right; the physicians' procedure ended up with more complications for the patient.

On how this affected the nurse's patient-care job, she said: 'I walked away and till date do not care to work with that arrogant physician. I feel for his patients.' In general, a large $50 \%$ of the nursing sample shared varied experiences of physicians' verbal coercion and use of argumentum ad expertiteto undermine the other party's concerns. Nurses report that senior physicians 'do this a lot to their younger colleagues' and nurses instead of using these opportunities as didactic and team building moments.

\section{Avoidance}

In this dynamic, a party withdraws and becomes an 'avoider', caring less about their own position or of the other party's interests. The priority is to avoid all disputes; they simply shut down. This approach may be useful in trivial conflicts or when a party predicts that further engaging in the conflict has potential damaging effects.

Searching for cultural socializations on how conflicts are handled, $10 \%$ of the sample stated that (a) with siblings, they find amicable ways to resolve the issue'; (b) with peers, $10 \%$ said they would report to school authorities. With bullies, (c) $20 \%$ stated that they fight back. A large $60 \%$ reported avoidance as their coping mechanism. Terms used to express this mechanism includes: 'I walk away'; 'I ignore them'; ' I keep my ideas to myself'; 'I avoid teaming with them'; 'I cannot stand them" and 'I become just unhappy and work on my own'. These findings are crucial since they define team disunity and silo functioning in healthcare that should be characterized by cognitive, supportive, and concerted team work. Beyond the scope of the question of how nurses deal with bullies and authoritarian physicians, they reported that the abuse has vertical and horizontal dimensions. Physicians bully nurses just as nurses bully other nurses. In both dimensions, avoidance is the preferred defence mechanism. 'Some nurses refuse to join interdisciplinary ward rounds on patients assigned to them. In some case, they refuse to meaningful contribute to the clinical discussion on the patient's progress or deterioration. These deficits may amount to adverse medical events, the lowering of quality healthcare delivery, and reveal how nurses predominantly handle work conflicts in Nigeria.

\section{Compromise}

This position reflects an intermediate level of concern for both sides. In the case of a conflict of opinion, the nurse will look for a solution that gives both nurse and doctor something of what each wanted. From this study, no nurse showed a willingness to compromise, dialogue, or negotiate with the doctor in order to reach an agreement. This is telling with regards to how nurses have been socialized to resolve conflict.

Yet, when asked the meaning of collaboration and to suggest models, these nurses defined collaboration as the integration of viewpoints, an exchange of information and appraisal of the issues in dispute in order to reach a solution acceptable to both parties. In complex conflicts, this approach facilitates and extracts the best of the talents and knowledge of both sides, allowing them to reach and apply a successful solution to the problem. They add that role separations and clear definitions of competence may facilitate nurse/physician collaboration. 


\section{Discussion}

Our cultural and social up-bringing shapes a large portion of who we become and how behave in the human society: how we speak, gender roles, reactions to conflict, and how we make choices. The family model also represents the child's entire social world, dealing with male and authoritarian figures as parents did. Avoidance in conflict situation is a learned response to an aggressor to ward off further attacks. The escape-avoidance theory is a non-violent form of retaliatory aggression in that it also is a means of defending oneself against future attacks [44]. Avoidance helps to eliminate the aversive stimuli, and creates a residual hatred against the aggressor.

In this study, nurses reported a strong preference not to confront conflict directly. In Kilmann and Thomas' [45] model for conflict resolution, nurses in conflict with other staffers (doctors, nurses, etc.) were found to lean towards the tactics of avoidance and compromise, the senior nurses tending to compromise while rank-and-file nurses chose avoidance [46]. This suggests that status and authority might be factors in the choice of conflict-resolution tactic. While this perspective is valid, this study showed a predominance of avoidance in dealing with conflict, gained from how these nurses were socialized to deal with male, bullying, and authoritative figures. Jones et al. proposed that nurses tend towards avoidance from feelings of powerlessness, taking this approach because they think they have only a slender chance of solving a problem as they think it should be solved. Jones et. al captured this helpless feelings of nurses in Nigeria, regardless of their professional or social status.

Within healthcare practice, with a strong clamour for safe and exceptional patient care, coordinated and teamed clinical performance is indispensable. Isolated or silo performance, dysfunctional teams, and feuding partners in the task of patient care, do more harm than good. When nurses avoid physicians in the continuum of care for a patient, that care quality diminishes. Interdisciplinary collaborative team care is required because only so much can be achieved by a single individual or group of professionals [47]. Healthcare practice in Nigeria therefore should have little room for communication breakdown, dysfunctional and conflicting team members. No matter what and how team members address and relate to one another, the exceptional care that patients expect should not be undermined.

\section{Recommendations}

The three constructs of nurse-physician collaboration that were identified in this research: sharing of patient information, joint participation in the care and in the decision-making process, and degree of cooperation, must be carefully scrutinized and implemented with the added input of nurses and physicians. This collaboration should encompass "four communication dimensions: frequency, timeliness, accuracy, and problem-solving, and three relationship dimensions: shared goals, shared knowledge and mutual respect" [47]. However, the frequency of patient conferences or rounding is an insufficient indication of collaboration. The fact that interdisciplinary conferences are held very frequently does not mean that the participants discuss matters freely and openly. This is truer in teams where nurses avoid physicians.

Providing a safe work environment where nurses can practice without fear or threat of aggression is acknowledged as a critical global issue for healthcare organizations [48]. In Nigerian hospitals, the issue has higher effects within the continuum of care for patients, and the lack of support and care for nursing caregivers. Although there has been growing recognition that workplace bullying is one of the most concerning forms of aggression experienced by nurses, to date, Nigerian hospital administrators have made little progress in developing explanatory models to stem these work stifling attitudes. There is the need, therefore, to strengthen and redefine nursing competencies and collaboration models that are cognizant of organizational characteristics and imbued with nurse/physician communication didactics. Such models will have important implications for the management of bullying, identifying creative interventions and ways to address these features of workplace climate. In particular, these efforts may help physician become mindful of their domineering behaviours. Nurses may also unlearn their avoidance behaviours in clinical setting.

Despite concerns with the interpersonal and inter-professional conflict within nurse-physician relationships, there are few conflict communication courses available for nurses in Nigerian hospitals. Further conflict-related nursing education is greatly needed for both staff nurses and nurse managers. Efforts towards enhanced communication may be a response to improved nurse-physician relationship, patient safety, and decreased length of stay in hospitals with a critical effect on clinical decision making and patient turnover.

Supportive and collaborative communication from matrons is very important for nurses coping with ambiguities related to managed-care [49]. The teaching of practical conflict management strategies that are cognizant of the significant cultural ways of dealing with conflict among nurses may be useful in the Nigerian healthcare environment. Nurse Matrons and, or Human Relationship Development Officers may choose to use a primary form of conflict coaching: a one-on-one process to develop a client's conflict understanding, interaction strategies and/ or interaction skills [19]. This coaching method will also avail nurses a number of support systems as they proactively or reactively handle conflict with others. This method helps to develop "communication skills; effectively applying conflict styles; preparing for negotiation; and integrating other dispute resolution processes" [50]. Such on the job training would provide opportunities for these nurses to master and experience organization theory, assertive behaviour, problem-solving, conflict resolution and building good workplace relationships.

In healthcare, perception is reality. The behaviours of matrons that staff nurses perceive as supportive will encourage them to make sound clinical judgments within well-functioning teams. Sampled nurses, in this research, would like to know that they have managers who are not timid but are willing to proactively deescalate tensions and crisis within interdisciplinary teams. Such managers should be diplomatic, fair, and honest in resolving conflicts; 'watching our back'; 'seeing to it that we have the staffing and resources we need'; 'providing both positive and negative feedback'; 'being accessible, approachable, and safe'; promoting staff cohesiveness and sound decision making'; 'making it possible for us to attend educational programs', and 'walking the talk'.

Effective performance of the nurse manager or matron role is key to the empowerment of staff that is essential to work effectiveness, and for nurses to function autonomously for patient safety and quality care [51]. The promotion of collegial relationships between physicians and nurses has equal good outcomes for patients [52].

\section{Conclusions}

This phenomenological research sieved through the lived experiences of nurses in Nigeria to ascertain if cultural socializations complicate conflict resolution between nurses and physicians, and if it further adversely affects patient care delivery. The results are in 
Citation: Okhakhu EE, Okhakhu AL, Okhakhu JOO (2014) Managing Organizational Conflicts: A Phenomenological Study of Nurse/Physician Conflicts in Nigerian Hospitals and their Impact on Managed Care Delivery. J Entrepren Organiz Manag 3: 115. doi: 10.4172/2169-026X.1000115

Page 5 of 6

the affirmative. In Nigeria, cultural socialization weighs heavily on how conflicts are handed, and have a negative impact on exceptional healthcare delivery. The continued or perceived dominance or professional superiority of physicians over nurses has adverse effect on nursing practice.

Avoidance, a non-violent form of retaliatory aggression and a means of defending oneself against future attacks [44] is the main way that Nigerian nurses eliminate aversive stimuli. This study's analyses of avoidance in nursing and patient care teams show negative impact on effective and exceptional healthcare delivery. This mechanism is destructive to collaborative and interdisciplinary patient care. Healthcare delivery should have no room for dysfunctional teams, silo performers, rude and uncooperative nurses and physicians. Such practitioners are cogs in the wheels of successful and exceptional healthcare delivery. Consequently, this research showed value for collegiality in patient care, and pointed to new direction in the understanding collaboration.

Healthcare delivery is about delivery; it is the delivery experience that matters. Patient exceptional experience is what distinguishes a good hospital from a great hospital. A good hospital tries to give just enough medicine and service to justify the money it takes from the patient. A great hospital strives to defy imaginations. Its goal is to provide an exceptional healthcare quality service than any amount of money could possibly pay for; more quality service experience than the nurses and physicians could be paid. From a naïve management perspective, this sounds like a recipe for bankruptcy. It is almost trying to avoid making money. Rather, this question should be: does it serve; does it add value to patient's recovery? If the answer is yes, it will make money on the long run, having created and sustains an ever growing pool of loyal customers. In other words, if our hospitals exceed patients and family expectations, patients will pay you even more. Yet the creation of a loyal customer base and service packaging for exceptional experience are impossible in conflicted healthcare environments.

\section{References}

1. Tabak N, Koprak O (2007) Relationship between how nurses resolve their conflicts with doctors, their stress and job satisfaction. Journal of Nursing Management 15: 321-331.

2. Morgan AP, McCann JM (1983) Nurse-physician relationships: the ongoing conflict. Nursing Administration Quarterly 7: 1-7.

3. Coeling HVE, Cukr PL (2000) Communication styles that pro-mote perceptions of collaboration, quality and nurse satisfaction. Journal of Nursing Care Quality 14: 63-74.

4. Corley MC (1998) Ethical dimensions of nurse-physician relations in critical care. The Nursing Clinics of North America 33: 325-337.

5. Corser WD (2000) The contemporary nurse-physician relationships: insights from scholars outside the two professions. Nursing Outlook 48: 263-269.

6. Erlen JA, Sereik SM (1997) Critical care nurses, ethical decision-making and stress. Journal of Advanced Nursing 26: 953-961.

7. Okhakhu E (2011) Human performance as a contributor to the culture of safety: A qualitative study of self-efficacy and self- cognition among healthcare professionals, Capella University, United States.

8. Cresswell JW (2003) Research design: Qualitative, quantitative, and mixed methods approaches. (2nd edn.) Sage, Thousand Oaks, London.

9. Cresswell JW (1998) Qualitative inquiry and research design: Choosing among the five traditions. Sage, Thousand Oaks, London.

10. Patton MQ (2002) Qualitative research and evaluation methods (3rd edn). Thousand Oaks, Sage London.

11. Folger JP, Poole MS, Stutman RK (2009) Working Through Conflict: Strategies for Relationships, Groups, and Organizations. Allyn and Bacon, MA.
12. Hillhouse JJ, Adler CM (1997) Investigating stress effect patterns in hospital staff nurses: results of a cluster analysis. Social Science and Medicine 45: 1781-1788.

13. Almost J (2006) Conflict within nursing work environments: concept analysis Journal of Advanced Nursing 53: 444-453.

14. Farrell GA (1997) Aggression in clinical settings: nurses views. Journal of Advanced Nursing 25: 501-508.

15. Hesketh KL, Duncan SM, Estabrooks CA (2003) Workplace violence in Alberta and British Columbia hospitals. Health Policy 63: 311-321.

16. Espeland KE (2006) Overcoming burnout: How to revitalize your career. The Journal of Continuing Education in Nursing 37: 178-184.

17. Cox KB (2003) The effects of intrapersonal, intra-group, and intergroup conflict on team performance effectiveness and work satisfaction. Nursing Administration Quarterly 27: 153-163.

18. Lambert VA, Lambert CE, Ito M (2004) Workplace stressors, ways of coping and demographic characteristics as predictors of physical and mental health of Japanese hospital nurses. International Journal of Nursing Studies 41: 85-97.

19. Brinkert R (2006) Conflict coaching: advancing the conflict resolution field by developing an individual disputant process.Conflict Resolution Quarterly 23 517-528.

20. Wilmot WW, Hocker $J L$ (2007) Interpersonal Conflict ( $7^{\text {th }}$ edn.). McGraw Hill Boston, MA.

21. Keung WFV, Chair SY (2006) Case study: reflections of a critical care nurse on futile treatment. CONNECT: The World of Critical Care Nursing 5: 71-74.

22. Silen M, Svantesson M, Ahlstrom G (2008) Nurses conceptions of decision making concerning life-sustaining treatment. Nursing Ethics 15: 160-173.

23. Halcomb E, Daly J, Jackson D, Davidson P (2004) An insight into Australian nurses experience of withdrawal/with-holding of treatment in the ICU. Intensive and Critical Care Nursing 20: 214-222.

24. Frederich, ME, Strong R, von Gunten CF (2002) Physician-nurse conflict: Can nurses refuse to carry out doctors orders? Journal of Palliative Medicine 5 $155-158$.

25. Robinson F, Cupples M, Corrigan M (2007) Implementing a resuscitation policy for patients at the end of life in an acute hospital setting: qualitative study. Palliative Medicine 21: 305-312.

26. Davies J, Lynch F (2007) Pushing boundaries in paediatric intensive care: Training as a paediatric retrieval nurse practitioner. Nursing in Critical Care 12: 74-80.

27. Buback D (2004) Home study program: assertiveness training to prevent verbal abuse in the OR. AORN Journal 79: 148-164.

28. Farrell GA (1999) Aggression in clinical setting: Nurses views - a follow-up study. Journal of Advanced Nursing 29: 532-541.

29. Chase SK (1995) The social context of critical care clinical judgment. Heart and Lung 24: 154-162.

30. Weinert CR, Chlan L, Gross C (2001) Sedating critically ill patients: factors affecting nurses delivery of sedative therapy. American Journal of Critical Care 10: $156-157$

31. Nicolson P, Burr J, Powell J (2005) Becoming an advanced practitioner in neonatal nursing: A psychosocial study of the relationship between educational preparation and role development. Journal of Clinical Nursing 14: 727-738.

32. Brand SL (2006) Nurses roles in discharge decision making in an adult high dependency unit. Intensive and Critical Care Nursing 22: 106-114.

33. Girard NJ (2008) Dealing with a surgical personality. AORN Journal 88: 479

34. Lingard L, Reznick R, DeVito I, Espin S (2002) Forming professional identities on the health care team: discursive con-structions of the other in the operating room. Medical Education 36: 728-734.

35. Arford,PH (2005) Nurse-physician communication: An organizational accountability. Nursing Economics 23: 72-77.

36. Kohn IT, Corrigan JM, Donaldson MS (2000) To Err is Human: Building a Safe Health System. Committee on Quality of Health Care in America, Institute of Medicine. National Academy Press, Washington DC, USA. 
Citation: Okhakhu EE, Okhakhu AL, Okhakhu JOO (2014) Managing Organizational Conflicts: A Phenomenological Study of Nurse/Physician Conflicts in Nigerian Hospitals and their Impact on Managed Care Delivery. J Entrepren Organiz Manag 3: 115. doi: 10.4172/2169-026X.1000115

37. Page A (2004) Keeping patients safe: Transforming the work environment of nurses. Committee on the Work Environment for Nurses and Patient Safety. Institute of Medicine. National Academy Press, Washington DC, USA

38. Tammelleo AD (2002) Nurses failed to advocate for their patient. Nursing Law: Regan Report 42: 2.

39. Danna K, Griffin RW (1999) Health and well-being in the workplace: A review and synthesis of the literature. Journal of Management 25: 357-384.

40. De Dreu CKW, Harinck F, Van Vianen AEM (1999) Conflict and performance in groups and organisations. International Review of Industrial and Organisational Psychology, 14: 376-405.

41. Manderino MA, Berkey N (1997) Verbal abuse of staff nurses by physicians. Journal of Professional Nursing 13: 48-55.

42. Watson V, Steiert MJ (2002) Verbal abuse and violence: The quest for harmony in the OR. Social Science and Medicine 8: 16-22.

43. Rahim MA, Bonoma TV (1979) Managing organizational conflict: a model for diagnosis and intervention. Psychological Reports 44: 1323-1344.

44. Baron BA, Richardson DR (1994) Human aggression. (2nd edition). NY: Plenum.
45. Kilmann RH, Thomas KW (1977) Developing a forced choice measure of conflict-handling behavior: The MODE instrument. Educational and Psychological Measurement 37: 309-325.

46. Cavanagh SJ (1991) The conflict management style of staff nurses and nurse managers. Journal of Advanced Nursing 16: 1254-1260.

47. Ushiro R (2009) Nurse-Physician Collaboration Scale: development and psychometric testing. Journal of Advanced Nursing 65: 1497-1508

48. Hutchinson M, Jackson D, Wilkes L, Vickers M (2008) A new model of bullying in the nursing workplace: Organizational characteristics as critical antecedents. Advances in Nursing Science 31: 60-71.

49. Apker J (2001) Role development in the managed care era: A case of hospitalbased nursing. Journal of Applied CommunicationResearch 29: 117-136.

50. Brinkert $R$ (2011) Conflict coaching training for nurse managers: A case study of a two-hospital health system. Journal of Nursing Management,19: 80-91.

51. Laschinger HK, Wong C, McMahon, Kaufman C (1999) Leader behavior impact on staff nurse empowerment, job tension, and work effectiveness. J Nurs Adm. 29: 28-39.

52. Schmalenberg CE, Kramer M (2009) Nurse manager support: How do staff nurses define it? Critical Care Nurse 29: 61-69. 